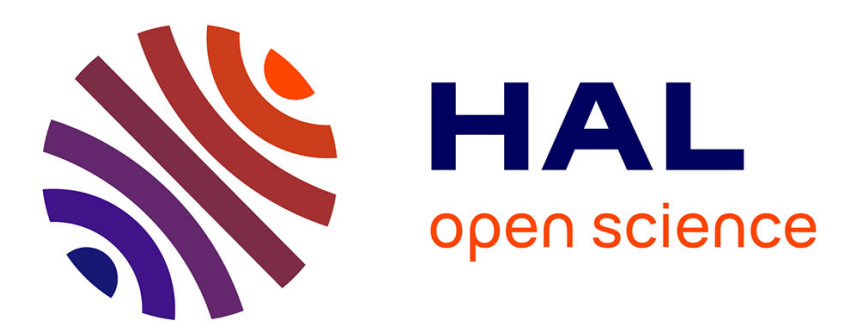

\title{
Crystallization of Nanodomains in Polyethylene Latexes
}

Fabrice Brunel, Guilhem Billuart, Pierre-Yves Dugas, Muriel Lansalot, Elodie

Bourgeat-Lami, Vincent Monteil

\section{To cite this version:}

Fabrice Brunel, Guilhem Billuart, Pierre-Yves Dugas, Muriel Lansalot, Elodie Bourgeat-Lami, et al.. Crystallization of Nanodomains in Polyethylene Latexes. Macromolecules, 2017, 50 (24), pp.9742 9749. 10.1021/acs.macromol.7b01930 . hal-01703299

\section{HAL Id: hal-01703299 \\ https://hal.science/hal-01703299}

Submitted on 22 Dec 2021

HAL is a multi-disciplinary open access archive for the deposit and dissemination of scientific research documents, whether they are published or not. The documents may come from teaching and research institutions in France or abroad, or from public or private research centers.
L'archive ouverte pluridisciplinaire HAL, est destinée au dépôt et à la diffusion de documents scientifiques de niveau recherche, publiés ou non, émanant des établissements d'enseignement et de recherche français ou étrangers, des laboratoires publics ou privés. 


\section{Crystallization of Nano-domains in Polyethylene Latexes}

Fabrice Brunel, ${ }^{*}$ Guilhem Billuart, Pierre-Yves Dugas, Muriel Lansalot, Elodie Bourgeat-Lami, and Vincent Monteil*

Univ. Lyon, Université Lyon 1, CPE Lyon, CNRS, UMR 5265, Chemistry, Catalysis, Polymers and Processes (C2P2), 43 Bvd. du 11 Novembre 1918, F-69615 Villeurbanne, France

E-mail: fabrice.brunel@univ-lyon1.fr; vincent.monteil@univ-lyon1.fr 


\begin{abstract}
Semi-crystalline polyethylene (PE) nanoparticles were obtained by free radical emulsion polymerization under mild conditions of pressure and temperature. At high surfactant concentration, the obtained anisotropic nanoparticles exhibit a strong degree of supercooling. This paper explores the relationship between the morphology of such particles and their high degree of supercooling. The shape anisotropy of the semi-crystalline PE particles already observed by transmission electron microscopy was confirmed by dynamic light scattering with the autocorrelation function containing both translational and rotational diffusion coefficients as well as by in situ synchrotron small-angle and wide-angle X-ray scattering (SAXS/WAXS). Temperature-resolved synchrotron scattering was used to further characterize the evolution of particles morphology and crystallinity during cooling. Paying special attention to the role of the surfactant we propose a novel mechanism which contributes to a better understanding of the crystallization of PE nanoparticle. The observed supercooling might be the result of the Coulomb repulsion between the surfactant head groups present at the particle surface, which hinders the particle contraction upon crystallization. The high surface charge density prevents the reduction of the particle surface, thus forcing a morphological transition from sphere to oblate ellipsoid during crystallization. This mechanism would act as potential barrier to the crystallization, resulting in supercooling.
\end{abstract}




\section{Introduction}

Polyethylene (PE), the top manufactured polymer, is synthesized from either very sensitive and hazardous organometallic catalysts (i.e. Ziegler-Natta catalysis) $)^{1-5}$ or by an energy intensive process $\left(200-300^{\circ} \mathrm{C}, 2000\right.$ bar) using free-radical polymerization (FRP). ${ }^{6-9}$ In the latter case a branched, low-density polyethylene (LDPE) is produced, which exhibits low crystallinities and melting temperatures. Suspensions of LDPE particles in water are used as wax dispersions in cement, bitumens and in the papermaking industry. Such dispersions are obtained by mixing melted polymer with water at high temperature followed by a high-pressure homogenization step in order to reduce the polymer particle size down to $\approx 2$ $\mu \mathrm{m} .{ }^{10-13}$ This process is however energy consuming. We have recently developed the direct synthesis of PE nanoparticles by FRP in water under mild conditions of pressure and temperature $\left(\mathrm{T} \approx 70^{\circ} \mathrm{C}\right.$ and $\mathrm{P} \approx 50$ bar), which could advantageously replace the above mentioned processes. ${ }^{14,15}$ Indeed, ethylene polymerization in aqueous medium has been achieved by using a water-soluble initiator, either cationic or anionic. The PE particles were assumed to be stabilized by charged initiator fragments located at the polymer chain ends. Improved stabilization was obtained through the addition of a surfactant bearing the same charge as the initiator. In both cases, increasing the surfactant concentration led to higher yield of smaller particles with a high polydispersity, as determined by dynamic light scattering. ${ }^{15}$ The high polydispersity of the PE nanoparticles, obtained in the presence of surfactant, was attributed to non-spherical, disk-like particle morphologies whereas surfactant-free systems always led to spherical particles. Another difference between PE latexes obtained with or without surfactant was the degree of supercooling. PE latex obtained with surfactant exhibits a much lower crystallization temperature compared to the surfactant-free latex. Supercooling is usually attributed to the occurrence of homogeneous nucleation. In a bulk material, the presence of heterogeneities lowers the activation barrier to nucleation (i.e. heterogeneous nucleation). When the number of micro-domains is several orders of magnitude higher than the number of heterogeneities, heterogeneous nucleation can completely disappear. In this case, highly 
confined isolated nano-domains can undergo homogeneous nucleation. Such nucleation requires a much higher activation barrier thus lowering the crystallization temperature (i.e. increased supercooling). The enhanced supercooling of confined PE chains has been evidenced in various systems such as: droplet dispersions, ${ }^{16-18}$ immiscible polymer blends, ${ }^{19,20}$ block copolymers, ${ }^{21-25}$ and thin films. ${ }^{26,27}$ Crystallization kinetics are often described using the Avrami equation: ${ }^{28-30}$

$$
v_{c}=\exp \left(-k t^{n}\right)
$$

Where $k$ is the overall crystallization rate constant, $n$ the Avrami exponent ranging from 1 to 4 and related to the dimensionality of nucleation and growth and $v_{c}$ is the relative volumetric transformed fraction. The Avrami exponent can be considered, as a first approximation, to be composed of two terms, ${ }^{31} n=n_{n}+n_{g d}$, where $n_{g d}$ is the fraction of the exponent related to the growth dimensionality ranging from 1 to 3 for one-dimensional to three-dimensional growth, while the nucleation term $\left(n_{n}\right)$ can have values from 0 to 1 by considering that nucleation can be instantaneous $\left(n_{n}=0\right)$ or sporadic $\left(n_{n}=1\right)$. Müller et al. compiled the Avrami exponent values obtained for several systems and observed a decrease of the Avrami exponent with increasing degree of confinement. ${ }^{32}$ Some authors have reported Avrami indices around 1 or lower, which should rule out the possibility of an homogeneous nucleation because $n=1$ could only be obtained when the nucleation is instantaneous and the growth is one-dimensional. According to classical nucleation theory, a rapid (instantaneous) nucleation rate implies a low energy barrier and thus heterogeneous nucleation. However, considering that growth is very fast and confined in all three dimensions of space, the crystallization kinetics is completely dominated by the nucleation process (i.e. $n_{g d}=0$ ). The low value of the Avrami exponent obtained under strong confinement could therefore be consistent with an homogeneous nucleation. However, discriminating between growth and nucleation in the Avrami equation is not straightforward and the intensity of the supercooling at high degree of confinement remains the best proof of the occurrence of homogeneous nucleation. Recently, extremely large supercooling of PE single lamellae has been achieved. ${ }^{33,34}$ The 
authors observed that the crystallization temperature evolved as a function of the crystal thickness. The relationship between the crystallization temperature and the crystal thickness was given by Strobl and implies the existence of an intermediate phase (mesomorphic phase) along the crystallization pathway. Evidence of a mesomorphic hexagonal phase of PE has been reported for short alkane chains $(\mathrm{n}<20)$ under pressure ${ }^{35,36}$ and with constrained ultra-drawn PE fibers. ${ }^{37,38}$ This is also supported by molecular dynamics simulations of supercooled PE melt, which reveal a stiffening of the chains prior to nucleation as well as an hexagonal arrangement of the chains in the critical nuclei. ${ }^{39-41}$ These simulations suggested that growth proceeds via alignment of segments close to the growth front, followed by lamella thickening through sliding of the segments from the amorphous regions into the crystalline regions. The lamella thickness can be related to the stability of the mesomorphic layer, i.e. the energy required during this lamellar thickening growth mechanism. A lower crystallization temperature could reduce the chain mobility and thus hinder the lamella thickening mechanism detailed above. However, a question remains: is the supercooling observed during the crystallization of confined polymer the result of a true homogeneous nucleation? There seems to be a vast consensus in the case of poly(ethylene oxide) (PEO) but, for PE, some authors believe that homogeneous nucleation has never been achieved so far. ${ }^{18}$

In this paper, we used synchrotron-SAXS and WAXS to investigate the supercooling of $\mathrm{PE}$ confined in nanoparticles obtained by free-radical emulsion polymerization. Cationic and anionic PE latexes were obtained using different initiating systems. In each case, PE latexes were prepared with and without the use of an ionic surfactant bearing the same charge as the initiator. In situ SAXS and WAXS measurements allowed us to confirm that the observed supercooling is associated with the rapid crystallization of thin PE lamellae (thickness $<10 \mathrm{~nm}$ ). The nucleation mechanism is discussed in the light of recent literature on PE crystallization. Special attention is given to the role of the surfactant which is often overlooked. Indeed the presence of surfactant is not only necessary in order to reduce the size of the nanoparticles, but it could also directly influence the nucleation during supercooling. 
Benefiting from these high degree of supercooling, potential application of these PE latexes as phase change material for thermal energy storage could be targeted. These PE dispersions would also represent an interesting model to study degradation of marine litter accumulated in the center of oceanic gyres (e.g. Great Pacific Garbage Patch).

\section{Methods}

Ethylene Polymerization. Surfactant-free anionic and cationic PE nanoparticles (named $\mathrm{A}_{0}$ and $\mathrm{C}_{0}$, respectively) were synthesized by emulsion polymerization. The synthesis of anionic PE nanoparticles using ammonium persulfate (APS) as initiator was previously described by Billuart et al. ${ }^{15}$ Cationic PE nanoparticles were obtained using 2,2'-azobis(2methylpropionamidine) dihydrochloride (AIBA) as initiator. ${ }^{14}$ For both systems, PE nanoparticles were also obtained with the use of a surfactant: sodium dodecyl sulfate (SDS) or cetyltrimethylammonium bromide (CTAB) for anionic and cationic latexes, respectively. These samples were named $\mathrm{A}_{S}$ and $\mathrm{C}_{S}$ (the subscript "S" corresponding to the presence of surfactant and the subscript "0" to the surfactant-free particles). A brief summary of the process as well as the synthesis conditions is given in supplementary material (Figure S1). The general characteristics of the obtained PE particles are given in Table 1.

Table 1: General characteristics of the studied PE nanoparticles.

\begin{tabular}{|c|c|c|c|c|c|c|c|}
\hline & Initiator (\%wt.) & Surfactant (\%wt.) & PE (\%wt.) & Solids Content $(\%)$ & $T_{c}\left({ }^{\circ} \mathrm{C}\right)^{a}$ & $\mathrm{Z}_{\text {ave }}^{b}(\mathrm{~nm})$ & poly $^{b}$ \\
\hline Cationic & AIBA & CTAB & & & & & \\
\hline $\mathrm{C}_{S}$ & 7.6 & 7.6 & 84.8 & 1.4 & 48.2 & 23 & 0.28 \\
\hline $\mathrm{C}_{0}$ & 2.7 & 0 & 94.6 & 1.6 & 70.2 & 79 & 0.01 \\
\hline Anionic & APS & SDS & & & & & \\
\hline $\mathrm{A}_{S}$ & 2.1 & 7.4 & 90.6 & 4 & 44.8 & 27 & 0.45 \\
\hline $\mathrm{A}_{0}$ & 5.6 & 0 & 94.4 & 1.5 & 60.3 & 82 & 0.03 \\
\hline
\end{tabular}


Dynamic Light Scattering (DLS). The intensity average hydrodynamic particle diameter $\left(Z_{\text {ave }}\right)$, the poly values and the $\zeta$-potential of the PE latexes were determined at $90^{\circ}$ and $173^{\circ}$ with a Zetasizer NanoZS (Malvern instrument Ltd, Worcestershire, UK) equipped with a $4 \mathrm{~mW} \mathrm{He} / \mathrm{Ne}$ laser beam operating at $\lambda=633 \mathrm{~nm}$. All measurements were performed at $25.0 \pm 0.2^{\circ} \mathrm{C}$. For spherical particles, a simple exponential decay was used to fit the autocorrelation function and the correlation decay rate was expanded in a power series (Cumulants methods) giving particle diameter and poly values. For the anisotropic particles, we used a two-decay exponential and Perrin friction factors to account for the translational and rotational diffusion coefficients (see the Supplementary Information pages S3 to S6 for more detail on the calculation). The $\zeta$-potential was derived from electrophoretic mobility measurements using the Smoluchowski's equation. ${ }^{42}$

Small and Wide-Angle X-ray Scattering (SAXS and WAXS). SAXS measurements were carried out at the BM02 beamline of the European Synchrotron Radiation Facilities (ESRF, Grenoble, France). Experiments were carried out at an energy of $25.5 \mathrm{keV}$ with a sample to detector distance of 164 or $16 \mathrm{~cm}$ for SAXS and WAXS, respectively, using a 1242 $\times 1152$ CCD camera. The recorded images were first corrected from dark current and flat field and normalized with respect to the intensity of the incident beam. The azimutal integration of the corrected images gave the radial integration (scattering curves). Finally the obtained scattering curves were calibrated (q-axis) using silver behenate and corrected for sample transmission and background subtraction. In order to study morphological changes during crystallization, the samples were heated up to $100^{\circ} \mathrm{C}$ to erase previous thermal history and allowed to cool down to $40^{\circ} \mathrm{C}$ while SAXS or WAXS intensities were recorded. 
SAXS measurements were analysed using SASfit 0.93.3 software. The form-factor equations used to fit the curves are given below for the different situation.

All melted particles were fitted using the form factor of a sphere:

$$
I_{\text {sphere }}(q, r, \Delta \eta)=\left(\frac{4}{3} \pi r^{3} \Delta \eta 3 \frac{\sin q r-q r \cos q r}{q r^{3}}\right)^{2}
$$

With $\mathrm{r}$ the radius of the sphere and $\Delta \eta$ the scattering length density difference between the PE particle and the water (i.e. $\Delta \eta=\eta_{\mathrm{PE}}-\eta_{\text {water }}$ ).

When crystallization arose $\left(T<T_{c}\right)$ for samples $A_{0}$ and $C_{0}$, a broad correlation peak (Teubner and Stray model ${ }^{43}$ ) was added to fit the high q-range:

$$
\begin{aligned}
I(q) & =\frac{8 \pi \Delta \eta / \xi}{a^{2}-2 b q^{2}+q^{4}} \\
a^{2} & =\left(k^{2}+1 / \xi^{2}\right)^{2} \\
b^{2} & =k^{2}-1 / \xi^{2}
\end{aligned}
$$

Where $\xi$ is the correlation length (length beyond which correlations die out), $d=2 \pi / k$ is the d-spacing (characteristic of the domain size or periodicity) and $\Delta \eta$ is the scattering length density contrast $\left(\Delta \eta=\eta_{\mathrm{PE} \text { crystallite }}-\eta_{\text {amorphous PE}}\right)$. 

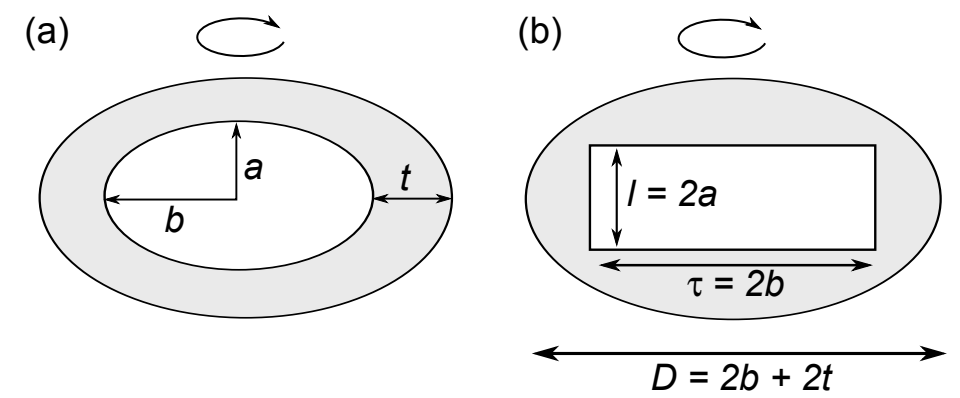

Figure 1: Representation of the geometrical parameters used for the different models. (a) SAXS ellipsoidal core-shell form factor: $a$ the semi-major axe of the elliptical core and $b$ the semi-minor axis of the elliptical core, $t$ the shell thickness. (b) Characteristic domain size , $\tau$, measured by WAXS, the long axis diameter, $D$, determined by DLS and the lamella thickness, $l$, determined by SAXS $(l \approx 2 a)$.

For $\mathrm{A}_{S}$ and $\mathrm{C}_{S}$, at $\mathrm{T}<\mathrm{T}_{c}$, the form factor of an ellipsoidal core-shell was used:

$$
\begin{aligned}
I_{E C S h} & =\int_{0}^{1}\left[\left(\eta_{\text {core }}-\eta_{\text {shell }}\right) V_{c}\left[\frac{3 j_{1}\left(x_{c}\right)}{x_{c}}\right]+\left(\eta_{\text {shell }}-\eta_{\text {solvent }}\right) V_{t}\left[\frac{3 j_{1}\left(x_{t}\right)}{x_{t}}\right]\right]^{2} \\
j_{1}(x) & =\frac{\sin (x)-x \cos (x)}{x^{2}} \\
x_{c} & =q \sqrt{a^{2} \mu^{2}+b^{2}\left(1-\mu^{2}\right)} \\
x_{t} & =q \sqrt{(a+t)^{2} \mu^{2}+(b+t)^{2}\left(1-\mu^{2}\right)} \\
V_{c} & =\frac{4}{3} \pi a b^{2} \\
V_{t} & =\frac{4}{3} \pi(a+t)(b+t)^{2}
\end{aligned}
$$

Where $a$ is the semi-principal axe of the elliptical core, $b$ the equatorial semi-axis of the elliptical core and $t$ the thickness of the shell (cf. Figure 1a). $V_{c}$ and $V_{t}$ are the volume of the core and the total volume of the core plus the shell, respectively, while $\eta_{\text {core }}, \eta_{\text {shell }}$ and $\eta_{\text {solvent }}$ are the scattering length densities of the core (crystalline PE), the shell (amorphous PE) and the solvent (water), respectively. The scattering length densities were calculated using sasfit SLD Calculator giving: $\eta_{\mathrm{PE} \text { crystallite }}=9.716 \times 10^{-10} \mathrm{~cm}^{-2}, \eta_{\text {amorphous PE }}=8.255 \times 10^{-10} \mathrm{~cm}^{-2}$ and $\eta_{\text {water }}=9.344 \times 10^{-10} \mathrm{~cm}^{-2}$. 
Figure 2 shows the two main peaks of the diffraction planes (110) and (200) observed by WAXS and characteristic of orthorhombic polyethylene. ${ }^{44}$

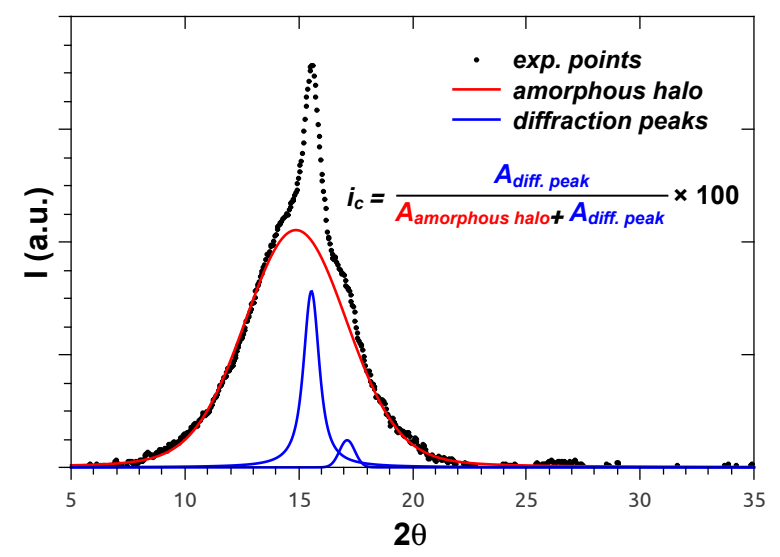

Figure 2: Diffraction pattern of PE latex and determination of the crystallinity index using log-normal peak fitting.

The diffraction peaks and the amorphous halo were fitted using a Gaussian function which allowed us to calculate a crystallinity index $\left(i_{c}\right)$ :

$$
i_{c}(\%)=\frac{\sum A_{\text {peak }}}{\sum A_{\text {peak }} \sum A_{\text {halo }}} \times 100
$$

Where $A_{\text {peak }}$ and $A_{\text {halo }}$ are the area of the crystalline peaks and the amorphous halo, respectively.

The characteristic domain size ( $\tau$ in Figure $1 b)$ is obtained from the Scherrer equation:

$$
\tau=\frac{K \lambda}{\beta \cos \theta}
$$

Where $\mathrm{K}$ is a dimensionless shape factor of about 0.9 under the assumption of a Gaussian line shape, $\lambda$ is the $\mathrm{X}$-ray wavelength, $\beta$ is the line broadening at half the maximum intensity, after subtracting the instrumental line broadening in radians (determined using silver behenate sample) and $\theta$ is the Bragg angle also in radians. 


\section{Results and Discussion}

At $100^{\circ} \mathrm{C}$, in the surfactant-free systems (i.e. samples $\mathrm{A}_{0}$ and $\mathrm{C}_{0}$ ), the scattering intensities of the melted particles clearly show wavelets characteristic of a spherical form factor (Figure 3a and c). These curves were fitted using a spherical form factor with a log-normal distribution (red curves in Figure $3 \mathrm{a}$ and c), giving a mean particle radius of around 38 and $35 \mathrm{~nm}$, for $\mathrm{A}_{0}$ and $\mathrm{C}_{0}$, respectively, and in both cases, a standard deviation, $\sigma$, of 0.05 . After cooling down to $40^{\circ} \mathrm{C}$ (Figure $3 \mathrm{~b}$ and $\mathrm{d}$ ) the particle size decreased and a broad correlation peak appeared at higher q-range indicating the presence of crystalline domains within the particles (see supplementary information Figure S4). We have plotted in Figure 4a the evolution of the particle radius with the temperature (i.e. during the cooling process). The size slowly decreased from 100 to $60^{\circ} \mathrm{C}$ where the particles suddenly shrink to smaller sizes. The evolution of the particle radius is consistent with the increase of the crystallinity index measured by WAXS (see Figure 5). During cooling from 100 to $40^{\circ} \mathrm{C}$, the diffraction peaks characteristic of orthorhombic PE appeared around $80^{\circ} \mathrm{C}$ and increased in intensity more or less steadily until about $60^{\circ} \mathrm{C}$ where a corresponding increase of crystallinity index is observed. At room temperature, large spherical nanoparticles were obtained $(\mathrm{R} \approx 35 \mathrm{~nm})$ as previously evidenced by TEM and DLS (Table 2). ${ }^{14,15}$

In the presence of surfactant (i.e. samples $\mathrm{A}_{S}$ and $\mathrm{C}_{S}$ ), the picture is quite different. At $100^{\circ} \mathrm{C}$, the scattering intensities of the melted particles $\left(\mathrm{A}_{S}\right.$ and $\left.\mathrm{C}_{S}\right)$ were also fitted using a spherical form factor (Figure 6a and c) giving much smaller particle radius of around 10.5 $\mathrm{nm}$. The evolution of the particle radius during cooling is reported in Figure 4b. The initial melted nanoparticles shrink down until a temperature of $65^{\circ} \mathrm{C}$ while remaining completely amorphous $\left(i_{c}=0\right.$ in Figure 5$)$. This is the logical consequence of the negative thermal expansion (i.e. "thermal contraction"). Between 65 and $55^{\circ} \mathrm{C}$, the particle radius remained 

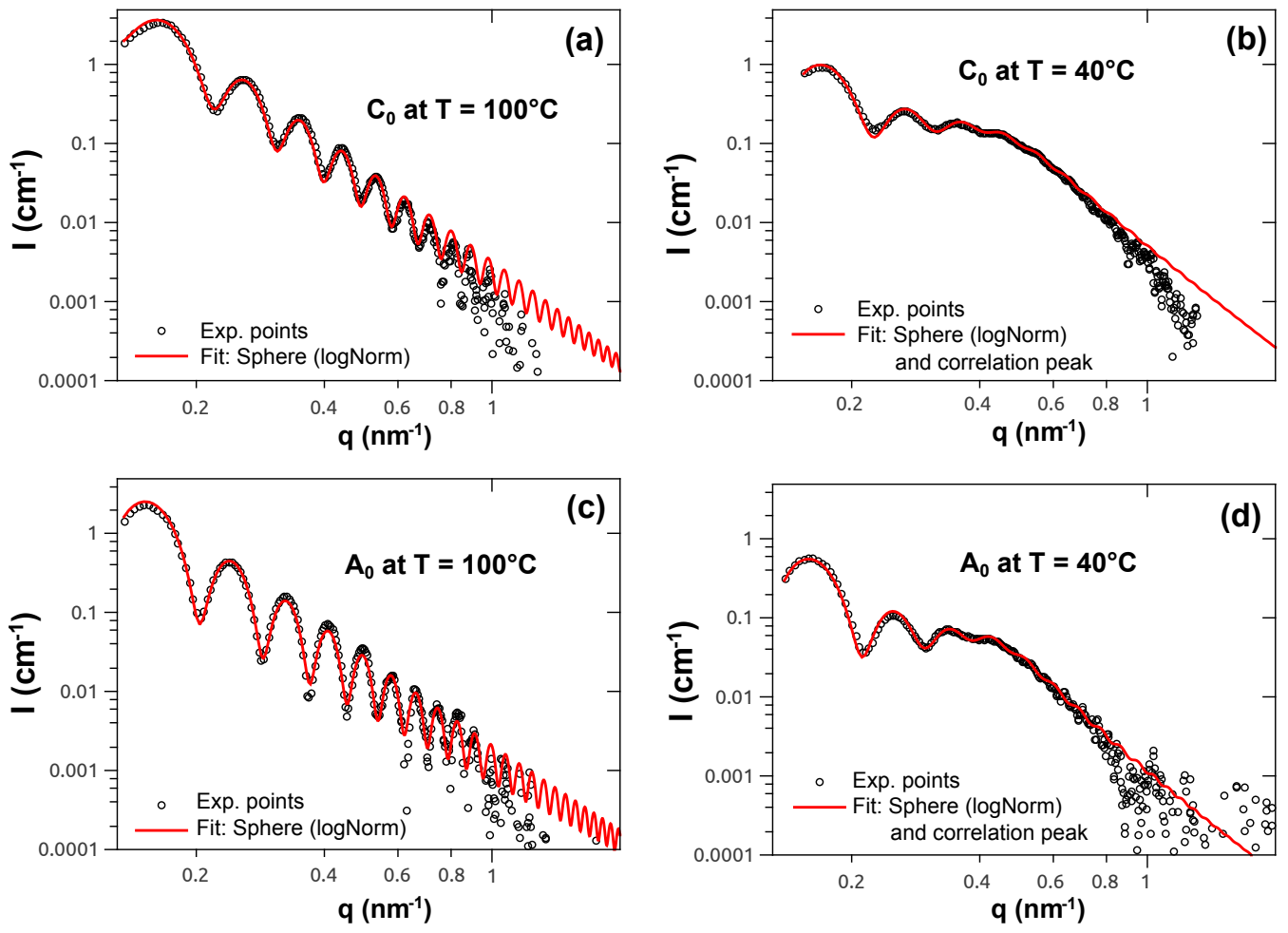

Figure 3: Synchrotron-SAXS analysis of PE latexes $\mathrm{C}_{0}$ (top) and $\mathrm{A}_{0}$ (bottom) obtained without surfactant at $100{ }^{\circ} \mathrm{C}$ (left) and $40{ }^{\circ} \mathrm{C}$ (right), Fitting curves: form factor of polydisperse spheres plus an additional correlation peak (Teubner and Stray model) at $40{ }^{\circ} \mathrm{C}$. Cationic $\left(\mathrm{C}_{0}\right)$ and anionic $\left(\mathrm{A}_{0}\right)$ particles were obtained using respectively AIBA or APS as initiator. 
more or less constant (Figure 4b) while crystallization was still not observed (i.e. the supercooling occurred). Around $55^{\circ} \mathrm{C}$ and $50^{\circ} \mathrm{C}$, for cationic $\left(\mathrm{C}_{S}\right)$ and anionic $\left(\mathrm{A}_{S}\right)$ particles, respectively, the crystallisation occurred suddenly (sharp bump in Figure 5). From the evolution of the crystallinity index, the Avrami exponent values could be calculated. One should note that, in the present work, the Avrami's exponents are derived from non-isothermal experiments, while such kinetic investigations are usually carried out isothermally. Indeed, the JMAK model assumes isokinetic conditions, i.e. nucleation and growth rates being time independent. However, in the present case, crystallization occurred very rapidly $\left(\Delta T<2^{\circ} \mathrm{C}\right)$ and therefore we can assume that the isokinetic criteria is satisfied. The Avrami exponent values were found to be 1.1 and 0.7 for $\mathrm{A}_{S}$ and $\mathrm{C}_{S}$, respectively. These results compare well with typical values obtained with other systems made of highly isolated PE micro-domains. In such confined systems, one can reasonably assume that the growth is limited in all three dimensions (i.e. point-like crystallization: $n_{g d}=0$ ), hence the crystallization kinetics is completely dominated by nucleation. Indeed, considering the enthalpy of fusion of $\mathrm{PE}(\Delta H)$ of $293 \mathrm{~J} \mathrm{~g}^{-1}\left(2.94 \times 10^{8} \mathrm{~J} \mathrm{~m}^{-3}\right)$ and the surface energy of PE crystal $(\sigma)$ of $0.7 \mathrm{~J} \mathrm{~m}^{-2}, 36,45$ the critical radius of the nuclei is about $5 \mathrm{~nm}\left(r^{*}=\frac{2 \sigma}{\Delta H}\right)$ which is of the same order of magnitude as the crystallite dimension (Table 2). In this case, the crystallization kinetics is considered to be dominated solely by the nucleation rate and thus the Avrami exponent is equal to the nucleation term $\left(n=n_{n} \approx 1\right)$, which suggests a sporadic (or homogeneous) nucleation.

Below $\mathrm{T}_{c}$, when a broad correlation peak was added to the spherical form factor, the obtained radius increased up to $12 \mathrm{~nm}$ which is physically unrealistic. Alternatively, the increase in particle dimension observed here was likely the result of a change in the particle morphology. Indeed, previous observation of both samples $A_{s}$ and $C_{s}$ by TEM showed a non-spherical morphology. ${ }^{14,15}$ DLS measurements indicates a small average particle diameter $\left(Z_{\text {ave }} \approx 25 \mathrm{~nm}\right.$ ) but very high poly values (poly $\approx 0.3-0.4$ ) compared to the surfactant free-system (poly $\approx 0.01-0.03$ ). A closer examination of the DLS auto-correlation function revealed the presence of a two-exponential decay, characteristic of two time-correlations (see 

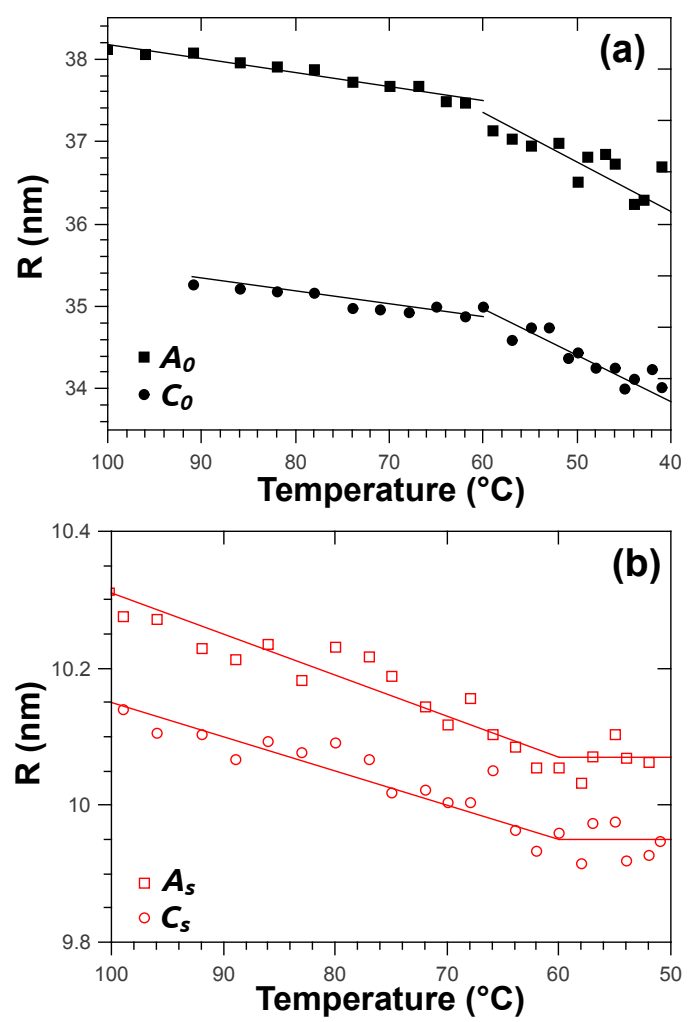

Figure 4: Evolution of the size of PE nanoparticles during cooling measured by SAXS. PE latexes obtained (a) in the absence of surfactant $\left(A_{0}\right.$ and $\left.C_{0}\right)$ and (b) in the presence of surfactant $\left(A_{S}\right.$ and $\left.C_{S}\right)$.

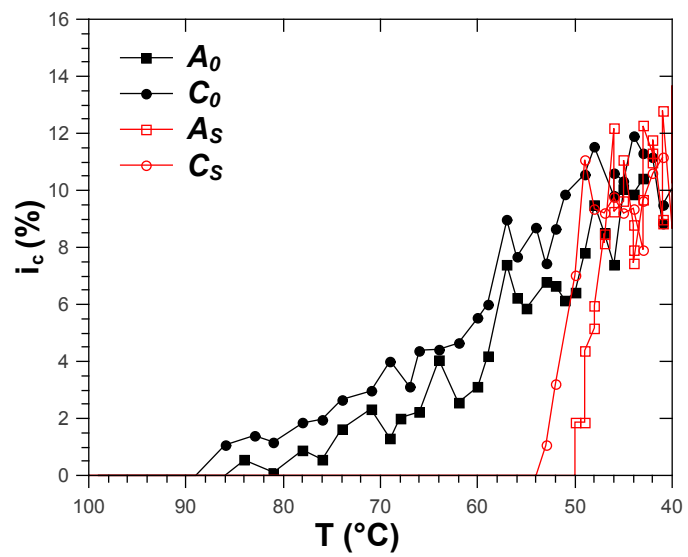

Figure 5: Evolution of the crystallinity of $\mathrm{PE}$ nanoparticles during cooling from $100^{\circ} \mathrm{C}$ to $40^{\circ} \mathrm{C}$. The crystallinity index is calculated as the ratio of crystalline peaks over the total area under the curve (i.e. crystalline peaks and amorphous halo). 
Supplementary Information, Figure S2). This second time-correlation remained at high dilution and after filtration $(0.22 \mu \mathrm{m})$ independently of the scattering angles $\left(90^{\circ}\right.$ or $\left.173^{\circ}\right)$, thus the presence of large or aggregated particles can be ruled out. The shape of the autocorrelation function could be the result of the non-spherical shape of the particles. For anisotropic particles, both translational and rotational motion must be considered because the light scattering depends on particle orientation. ${ }^{46-48}$ The Perrin friction factors were used to calculate the characteristic dimensions of the ellipsoidal particles using the rotational and translational diffusion coefficients determined from a double decay exponential fit of the autocorrelation function (cf. Figure S3, Supplementary Information). ${ }^{49-52}$ The results of these calculations are given in Table 2 and show good agreement with previous TEM observations. These results also compared well with SAXS-scattering intensities fitted using the form factor of a core/shell ellipsoid. Note that the size of the core obtained by SAXS also agreed with the dimensions of the crystallites measured by WAXS using the Scherrer equation (see Table S7 and S8 in the Supplementary Information).

Table 2: Summary of the PE particle dimensions at room temperature measured by synchrotron-SAXS and WAXS (Scherrer equation) and by DLS using either the cumulant method for spherical particles $\left(\mathrm{D}=Z_{\text {ave }}\right)$ or the translational and rotational diffusion coefficients for ellipsoidal particles (see Supplementary Information Table S2).

\begin{tabular}{c|ccc|c|cc}
\hline & $\mathrm{D}(\mathrm{nm})^{a}$ & $\epsilon^{a}$ & $\tau^{a}(\mathrm{~nm})$ & $\tau^{b}(\mathrm{~nm})$ & $\mathrm{D}(\mathrm{nm})^{c}$ & $\epsilon^{c}$ \\
\hline $\mathrm{A}_{0}$ & 72 & 1 & 15 & 14 & 82 & 1 \\
$\mathrm{C}_{0}$ & 66 & 1 & 15 & 15 & 79 & 1 \\
$\mathrm{~A}_{s}$ & 24 & 0.6 & 12 & 12 & 36 & 0.56 \\
$\mathrm{C}_{s}$ & 24 & 0.66 & 16 & 13 & 30 & 0.5 \\
\hline${ }^{a},{ }^{b}$ and ${ }^{c}$ measured by SAXS, WAXS and DLS respectively
\end{tabular}

$D$ is the longest diameter of the ellipse $\left(D=2 b+2 t\right.$ in Figure 1), $\epsilon=\frac{2 b+2 t}{2 a+2 t}$ the eccentricity of the ellipse ( $\epsilon=1$ for a sphere) and $\tau$ the size of the crystalline domains ( $\tau=2 b$, see

Figure 1). 

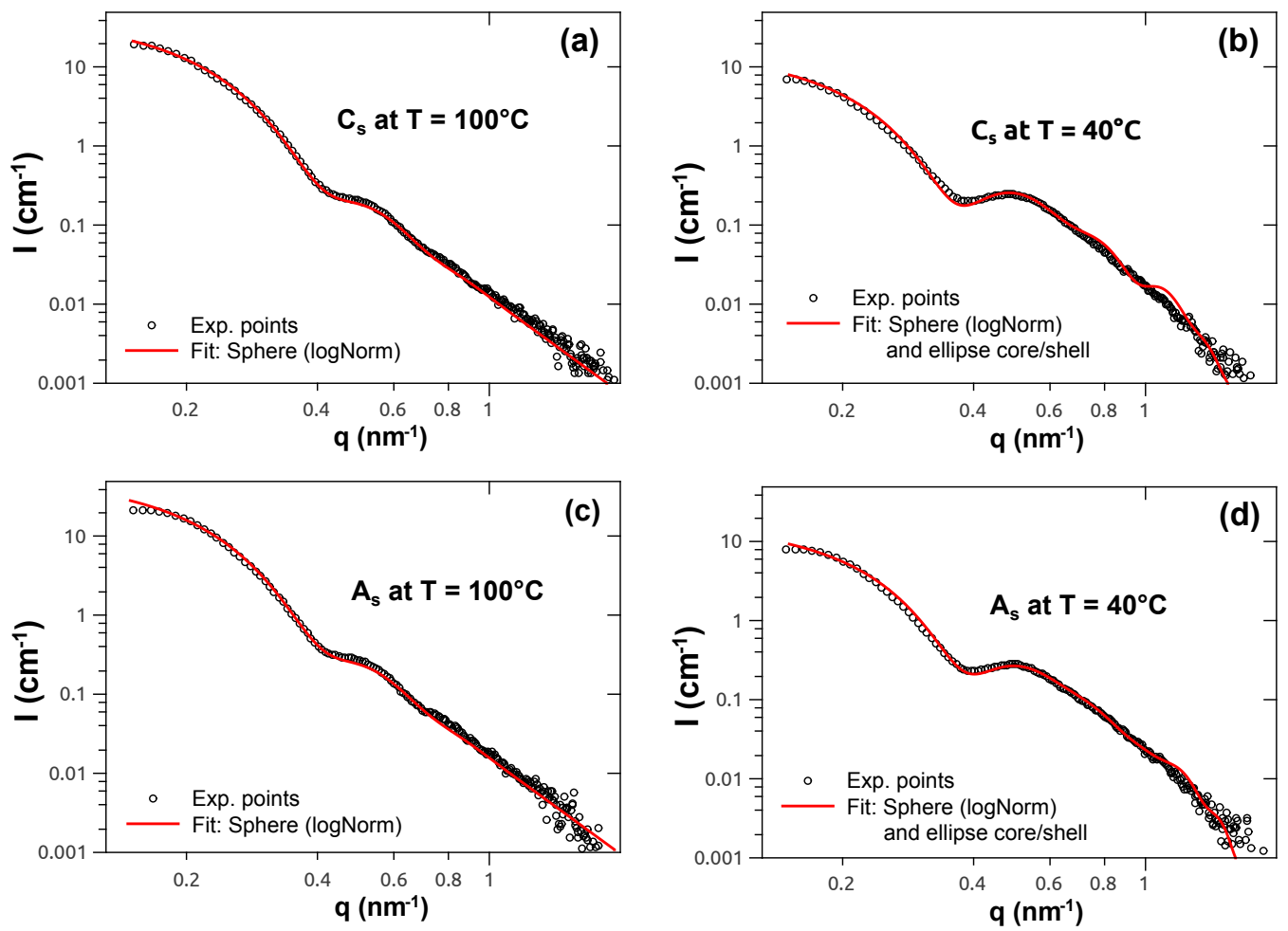

Figure 6: Synchrotron-SAXS analysis of PE latexes $\mathrm{C}_{S}$ (top) and $\mathrm{A}_{S}$ (bottom), obtained in the presence of surfactant at $100{ }^{\circ} \mathrm{C}$ (left) and $40^{\circ} \mathrm{C}$ (right). Fitting curves: spherical form factor at $100^{\circ} \mathrm{C}$ plus an additional ellipsoidal core/shell form factor at $40^{\circ} \mathrm{C}$. Cationic $\left(\mathrm{C}_{S}\right)$ and anionic $\left(\mathrm{A}_{S}\right)$ particles were obtained using respectively AIBA/CTAB and APS/SDS as initiator/surfactant systems. 
The crystal thickness $(8 \mathrm{~nm})$ determined by SAXS $(l=2 a$ in Figure $1 \mathrm{~b})$ and the crystallization temperature, $\mathrm{T}_{c}=45^{\circ} \mathrm{C}$, determined by $\mathrm{DSC},{ }^{14,15}$ fall on the same crystallization line as for single PE nanocrystals obtained by Weber et al. (in Figure 4 of $\operatorname{ref}^{33}$ ). The Gibbs-Thomson equation describes the evolution of the melting temperature as a function of the lamella thickness and has recently been extended to the crystallization temperature: ${ }^{37}$

$$
T \approx T_{m c}^{\infty} \frac{\left(2 \sigma_{a c}-2 \sigma_{a m}\right)}{\Delta H_{m c}} \frac{1}{l}
$$

With $T_{m c}^{\infty}$ the temperature of a virtual transition between the mesomorphic and the crystalline phases. $\sigma_{a c}$ and $\sigma_{a m}$ denote respective surface free energies between the amorphous phase and either the crystalline or the mesomorphic phases, $\Delta H_{m c}$ the heat of transition from the mesomorphic to the crystalline phase and $l$ the lamella thickness. The exact value of each constant from this extended-Gibbs-Thomson equation are still unknown but interestingly one could note that the crystallization line plotted by Weber et al. used the data obtained from rapid quenching of melted PE. In our case, the presence of a surfactant-covered surface could act as an "electrostatic quenching". The same would probably apply to Weber's nanocrystals obtained using the same anionic surfactant (SDS). The evolution of the particle radius during supercooling provides crucial evidence of the proposed "electrostatic quenching" mechanism. The nanoparticles obtained in the presence of surfactant showed very limited reduction in diameter, especially between 65 and $55^{\circ} \mathrm{C}$ (Figure $4 \mathrm{~b}$ ). In this temperature range, where the supercooling occurs, the dimensions of the particles remain more or less constant. In other words, the thermal energy removed from the nanoparticles is not compensated by the contraction of the polymer chains. This is equivalent to a significant drop of the internal pressure of the particles, i.e. a temperature decrease at constant volume. This de-pressurization of the nanoparticles artificially maintains the PE at a constant density instead of decreasing with the temperature, thus effectively hindering the crystallization. Such shrinkage hindrance can be the result of strong Coulombic repulsions between 
surfactant charged groups present at the particle surface. The thermal energy removed from the particles being stored as Coulomb repulsion on the particle surface, this prevents the shrinkage and crystallization of the particles during supercooling. The surface could hold this energy up to a point where the Coulombic repulsion becomes too strong so that the system reaches the Rayleigh instability limit. ${ }^{53}$ The Rayleigh critical radius $\left(r_{\text {limit }}\right.$, see Table S11 in the supplementary Information) that can be reached by PE particles was estimated from their surface charge $(Q)$ and the cohesion energy of PE in water $\left(\gamma=30 \mathrm{~J} \mathrm{~m}^{-2}\right)$.

$$
\begin{gathered}
Q=\sqrt{64 \pi \epsilon_{0} \epsilon_{r} \gamma r_{\text {limit }}^{3}} \\
\Rightarrow r_{\text {limit }}=\left(\frac{Q^{2}}{64 \pi \epsilon_{0} \epsilon_{r} \gamma}\right)^{1 / 3}
\end{gathered}
$$

where $\epsilon_{0}$ and $\epsilon_{r}$ are respectively the free space permittivity $\left(8.85 \times 10^{-12} \mathrm{~F} \mathrm{~m}^{-1}\right)$ and the relative permittivity of the solution $\left(79.1\right.$ for water at $\left.25^{\circ} \mathrm{C}\right)$. The surface charge was estimated assuming the presence of one initiator molecule per polymer chain and considering that all surfactant molecules are located at the surface of the nanoparticles. The calculated values of the Rayleigh critical radius (10.3 and $8.9 \mathrm{~nm}$ for $\mathrm{A}_{S}$ and $\mathrm{C}_{S}$, respectively) show good agreement with limiting particle radius during supercooling (Figure 4b) whereas for $\mathrm{A}_{0}$ and $\mathrm{C}_{0}$ the particle radius remains above the critical Rayleigh radius $\left(r_{\text {limit }}=24.9\right.$ and $11.3 \mathrm{~nm}$ for $\mathrm{A}_{S}$ and $\mathrm{C}_{S}$, respectively). Below $50-55^{\circ} \mathrm{C}$, the excess energy from the Coulomb repulsion can trigger the expulsion of a surfactant molecule from the surface. The ejection of one surfactant molecule will cause the surrounding neighbouring ones to follow in a process similar to a Coulomb explosion. These rapid movements of the surfactant molecules propagate along the surface as a shock wave which would strongly deform the particles. These contractions of the particle could set off the rapid crystallization of the PE into a single lamella and therefore cause the particles to collapse into an ellipsoidal shape. 


\section{Conclusions}

FRP of ethylene in aqueous medium under moderate pressure and temperature conditions yields small anisotropic PE nanoparticles which exhibit a high degree of supercooling. In situ synchrotron-SAXS/WAXS analyses of the crystallization kinetics and particle morphology confirmed many of the recent finding on PE crystallization in confined micro-domains. Low values of the Avrami exponent $(n \leq 1)$ are obtained under very strong confinement (nano-domain). In this case, the crystallization kinetics is dominated by the nucleation rate since the growth within such nanoparticles can be considered instantaneous. The enhanced supercooling observed with such small particles $(R \approx 10 \mathrm{~nm})$ scales as the inverse of the crystal thickness. According to Strobl's thermodynamic scheme, such relationship implies the existence of an intermediate phase (mesomorphic phase) along the crystallization pathway. The thickness of the lamella is the result of the reduced mobility of the PE chains at low crystallization temperature (high supercooling). Finally, we propose a novel mechanism (i.e.

"electrostatic quenching") explaining the origin of this enhanced supercooling in accordance with the evolution of the particle morphology. The change of morphology (from spherical to ellipsoidal particles) observed with small PE particles may be caused by the high charge density of the surface provided by the ionic surfactant. During cooling, the particles shrink down to the Rayleigh limit, hence provoking their strong deformation. These contractions could set off the rapid crystallization of the PE into a single lamella and therefore induce the collapsing of the particle into an ellipsoidal shape. The strong supercooling observed with these PE nanoparticles can thus be related to the occurrence of an homogeneous nucleation kinetic. However the high energy barrier responsible for this nucleation mechanism is provided by the Coulomb repulsion of the surfactant heads present at the surface and thus cannot be called true homogeneous nucleation.

Better understanding of PE crystallization is a field of tremendous interest because PE is employed in a multitude of applications due to its low cost and tunable semicrystalline properties. Among these applications, phase change material could be developed by taking 
advantage of the enhanced supercooling of confined PE. Furthermore, since PE is the most utilized plastic, these dispersions are well-suited for studying the degradation of PE waste in the environment, especially marine litter accumulated in the center of oceanic gyres.

\section{Conflict of Interest Disclosure}

The authors declare no competing financial interest

\section{Acknowledgement}

The authors thank Cyrille Rochas for his help on the ESRF: BM02 - D2AM French CRG Beamline. The authors thank R. Seguela, C. Chassenieux and T. Nicolay for fruitful discussions. ANR (Agence Nationale de la Recherche) and competitiveness clusters AXELERA and PLASTIPOLIS are acknowledged for financial support (project FRaPE; ANR 2011 JS08 $00801)$.

\section{Supporting Information Available}

Supporting information includes:

- Free radical emulsion polymerization process and synthesis conditions

- Dynamic Light Scattering raw data and analysis

- SAXS and WAXS spectra and fitting parameters

- Avrami analysis

- Rayleigh critical radius calculation 


\section{References}

(1) Ziegler, K.; Holzkamp, E.; Breil, H.; Martin, H. Das Mülheimer NormaldruckPolyäthylen-Verfahren. Angew. Chemie 1955, 67, 541-547.

(2) Natta, G.; Pasquon, I. The Kinetics of the Stereospecific Polymerization of $\alpha$-Olefins. Adv. Catal. 1959, 11, 1-66.

(3) Mark H.F., Kales N.M.B., Overberger C.G., Menges G., Encyclopedia of polymer science and engineering; WileyInterscience: New York, 1987; Vol. 6; pp 386-428.

(4) Mülhaupt, R. Catalytic polymerization and post polymerization catalysis fifty years after the discovery of Ziegler's catalysts. Macromol. Chem. Phys. 2003, 204, 289-327.

(5) Stürzel, M.; Mihan, S.; Mülhaupt, R. From Multisite Polymerization Catalysis to Sustainable Materials and All-Polyolefin Composites. Chem. Rev. 2016, 116, 1398-1433.

(6) Taylor, H. S.; Jones, W. H. The Thermal Decomposition of Metal Alkyls in Hydrogenethylen mixtures. J. Am. Chem. Soc. 1930, 52, 1111-1121.

(7) Flory, P. J. The Mechanism of Vinyl Polymerizations. J. Am. Chem. Soc. 1937, 59, $241-253$.

(8) Aggarwal, S. L. Polyethylene: Preparation, Structure, and Properties. Chem. Rev. 1966, 57, 665-742.

(9) Mark H.F., Kales N.M.B., Overberger C.G., Menges G., Encyclopedia of polymer science and engineering; WileyInterscience: New York, 1987; Vol. 6; pp 454-489.

(10) Stanley, G. A. (Ici Ltd). Production of aqueous dispersions of ethylene polymer. US Patent 2313144, 1943.

(11) Shimandle, D. J. (The B. F. Goodrich Company). Method for producing wax microspheres. US Patent 5185108, 1993. 
(12) Hunter, E. (Ici Ltd). Aqueous polyethylene dispersions produced by subjecting molten polymer in water to ahigh rate of shear. US Patent 2653919, 1953.

(13) Moncla, B. M.; Kalinowski, M. J.; Speth, D.; Diehl, C.; Schmidt, D.; Maak, K. D.; Wevers, R. (Mitsui Chemicals, Inc.). Aqueous dispersion, its production method, and its use. European Patent 0972794, 2005.

(14) Grau, E.; Dugos, P. Y.; Broyer, J. P.; Boisson, C.; Spitz, R.; Monteil, V. Aqueous dispersions of nonspherical polyethylene nanoparticles from free-radical polymerization under mild conditions. Angew. Chemie - Int. Ed. 2010, 49, 6810-6812.

(15) Billuart, G.; Lansalot, M.; Monteil, V. Free Radical Emulsion Polymerization of Ethylene. Macromolecules 2014, 47, 23-32.

(16) Massa, M. V.; Lee, M. S. M.; Dalnoki-Veress, K. Crystal nucleation of polymers confined to droplets: Memory effects. J. Polym. Sci. Part B Polym. Phys. 2005, 43, 3438-3443.

(17) Arnal, M. L.; Matos, M. E.; Morales, R. A.; Santana, O. O.; Müller, A. J. Evaluation of the fractionated crystallization of dispersed polyolefins in a polystyrene matrix. Macromol. Chem. Phys. 1998, 199, 2275-2288.

(18) Michell, R. M.; Blaszczyk-Lezak, I.; Mijangos, C.; Müller, A. J. Confinement effects on polymer crystallization: From droplets to alumina nanopores. Polymer 2013, 54, 4059-4077.

(19) Guo, Q. Phase behavior and crystallization in blends of a low molecular weight polyethylene-block-poly(ethylene oxide) diblock copolymer and poly(hydroxyether of bisphenol A). Thermochim. Acta 2006, 451, 168-173.

(20) Takeshita, H.; Gao, Y.-J.; Natsui, T.; Rodriguez, E.; Miya, M.; Takenaka, K.; Shiomi, T. Formation of phase structure and crystallization behavior in blends containing polystyrenepolyethylene block copolymers. Polymer 2007, 48, 7660-7671. 
(21) Michell, R. M.; Lorenzo, A. T.; Mu, A. J.; Lin, M.-c.; Chen, H.-l.; Blaszczyk-lezak, I.; Mart, J.; Mijangos, C. The Crystallization of Confined Polymers and Block Copolymers Infiltrated Within Alumina Nanotube Templates. Macromolecules 2011, 45, 1517-1528.

(22) Xu, J. T.; Ding, P. J.; Fu, Z. S.; Fan, Z. Q. Study of crystallization and melting behavior of polypropylene-block-polyethylenes copolymers fractionated from polypropylene and polyethylene mixtures. Polym. Int. 2004, 53, 1314-1320.

(23) Lorenzo, A. T.; Arnal, M. L.; Müller, A. J.; Boschetti De Fierro, A.; Abetz, V. Confinement effects on the crystallization and SSA thermal fractionation of the PE block within PE-b-PS diblock copolymers. Eur. Polym. J. 2006, 42, 516-533.

(24) Lorenzo, A. T.; Arnal, M. L.; Müller, A. J.; Boschetti-De-Fierro, A.; Abetz, V. Nucleation and isothermal crystallization of the polyethylene block within diblock copolymers containing polystyrene and poly(ethylene-alt-propylene). Macromolecules 2007, 40, 5023-5037.

(25) Yu, P. Q.; Xie, X. M.; Wang, Z.; Li, H. S.; Bates, F. S. Control of the confined and unconfined crystallization in glassy-crystalline poly(vinylcyclohexane)-b-poly(ethylene)-bpoly- (vinylcyclohexane) triblock copolymer in solution. Polymer 2006, 47, 1460-1464.

(26) Bernal-Lara, T. E.; Liu, R. Y. F.; Hiltner, A.; Baer, E. Structure and thermal stability of polyethylene nanolayers. Polymer 2005, 46, 3043-3055.

(27) Bernal-Lara, T. E.; Masirek, R.; Hiltner, A.; Baer, E.; Piorkowska, E.; Galeski, A. Morphology studies of multilayered HDPE/PS systems. J. Appl. Polym. Sci. 2006, 99, 597-612.

(28) Avrami, M. Kinetics of Phase Change. I - General theory. J. Phys. Chem. 1939, 7, $1103-1112$. 
(29) Avrami, M. Kinetics of Phase Change. II - Transformation-Time Relations for Random Distribution of Nuclei. J. Chem. Phys. 1940, 8, 212-224.

(30) Avrami, M. Kinetics of Phase Change. III - Granulation, Phase Change, and Microstructure Kinetics of Phase Change. J. Chem. Phys. 1941, 9, 177.

(31) Balsamo, V.; Urdaneta, N.; Pérez, L.; Carrizales, P.; Abetz, V.; Müller, A. J. Effect of the polyethylene confinement and topology on its crystallisation within semicrystalline ABC triblock copolymers. Eur. Polym. J. 2004, 40, 1033-1049.

(32) Müller, A. J.; Arnal, M. L.; Lorenzo, A. T. Crystallization in Nano-Confined Polymeric Systems. Handb. Polym. Cryst. 2013, 347-378.

(33) Weber, C. H.; Chiche, A.; Krausch, G.; Rosenfeldt, S.; Ballauff, M.; Harnau, L.; Göttker-Schnetmann, I.; Tong, Q.; Mecking, S. Single lamella nanoparticles of polyethylene. Nano letters 2007, 7, 2024-2029.

(34) Trzaskowski, J.; Rabe, C.; Vogtt, K.; Krumova, M.; Goerigk, G.; Ballauff, M.; Mecking, S. Anisotropic nanoparticles of precise microstructure polyolefins. Chemical Communications 2012, 48, 9153-9155.

(35) Gan, R. n-Alkane Homogeneous Nucleation: Crossover to Polymer Behavior. Macromolecules 2000, 33, 6174-6184.

(36) Sirota, E. B. Polymer crystallization: Metastable mesophases and morphology. Macromolecules 2007, 40, 1043-1048.

(37) Strobl, G. Crystallization and melting of bulk polymers: New observations, conclusions and a thermodynamic scheme. Prog. Polym. Sci. 2006, 31, 398-442.

(38) Yasuniwa, M. Hexagonal Phase of Polyethylene fibers under high pressure. Polym. J. 1991, 23, 1317-1324. 
(39) Yamamoto, T. Molecular dynamics simulations of polymer crystallization in highly supercooled melt: Primary nucleation and cold crystallization. J. Chem. Phys. 2010, $133,1-11$.

(40) Yamamoto, T. Molecular dynamics of polymer crystallization revisited: Crystallization from the melt and the glass in longer polyethylene. J. Chem. Phys. 2013, 139.

(41) Anwar, M.; Schilling, T. Crystallization of polyethylene: A molecular dynamics simulation study of the nucleation and growth mechanisms. Polymer 2015, 76, 307-312.

(42) Smoluchowski, M. V. Contribution to the theory of electro-osmosis and related phenomena. Bull. Int. Acad. Sci. Cracovie 1903, 3, 184-199.

(43) Teubner, M.; Strey, R. Origin of the scattering peak in microemulsions. J. Chem. Phys. 1987, 87, 3195-3200.

(44) Bunn, C. W. The crystal structure of long-chain normal paraffin hydrocarbons. The "shape" of the $\mathrm{CH}_{2}$ group. Trans. Faraday Soc. 1939, 35, 482-491.

(45) Strobl, G. From the melt via mesomorphic and granular crystalline layers to lamellar crystallites: A major route followed in polymer crystallization? Eur. Phys. J. E 2000, 3, 165-183.

(46) Eimer, W.; Pecora, R. Rotational and Translational Diffusion of Short Rodlike Molecules in Solution - Oligonucleotides. J. Chem. Phys. 1991, 94, 2324-2329.

(47) Aragón, S. R.; Pecora, R. Theory of dynamic light scattering from polydisperse systems. J. Chem. Phys. 1976, 64, 2395.

(48) Lucius, A. L.; Veronese, P. K.; Stafford, R. P. Methods Mol. Biol.; Springer Science \& Business Media, 2012; Vol. 796; pp 175-86. 
(49) Perrin, F. Mouvement Brownien d'un ellipsoide (II). Rotation libre et dépolarisation des fluorescences. Translation et diffusion de molécules ellipsoidales. J. Phys. le Radium 1936, 7, 1-11.

(50) Koenig, S. H. Brownian motion of an ellipsoid. A correction to Perrin's results. Biopolymers 1975, 14, 2421-2423.

(51) Matsuoka, H.; Morikawa, H.; Yamaoka, H. Rotational diffusion of ellipsoidal latex particles in dispersion as studied by depolarized dynamic light scattering. Colloids Surfaces A Physicochem. Eng. Asp. 1996, 109, 137-145.

(52) Hoffmann, M.; Wagner, C. S.; Harnau, L.; Wittemann, A.; I, P. C.; Bayreuth, U. 3D Brownian Diffusion of Submicron-sized Particle Clusters. ACS Nano 2009, 3, 1-24.

(53) Rayleigh, L. XX. On the equilibrium of liquid conducting masses charged with electricity. Philos. Mag. Ser. 5 1882, 14, 184-186. 


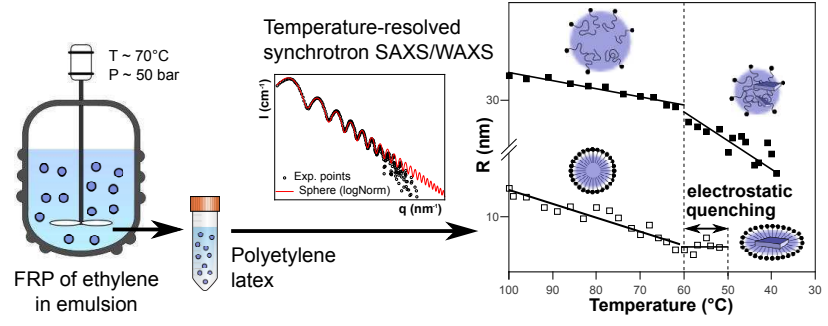

For Table of Contents Use Only 